\title{
Characterization of MWCNT-PEDOT: PSS Nanocomposite Flexible Thin Film for Piezoresistive Strain Sensing Application
}

\author{
Roopa Hegde $\left(\mathbb{D},{ }^{1}\right.$ Koona Ramji $\left(\mathbb{D},{ }^{2}\right.$ Swapna Peravali, ${ }^{3}$ Yallappa Shiralgi, \\ Gurumurthy Hegde, ${ }^{5}$ and Lavakumar Bathini ${ }^{6}$ \\ ${ }^{1}$ Centre for Nanotechnology, Andhra University College of Engineering (A), Visakhapatnam, India \\ ${ }^{2}$ Dr.B.R.Ambedkar University, Srikakulam, India \\ ${ }^{3}$ Department of Instrumentation Technology, Andhra University College of Engineering (A) Visakhapatnam, India \\ ${ }^{4}$ Department of Chemistry, Gokhale Centenary College, Ankola, Uttara Kannada, India \\ ${ }^{5}$ Centre for Nano-Materials \& Displays, B.M.S. College of Engineering, Bull Temple Road, Basavanagudi, Bengaluru, India \\ ${ }^{6}$ International Advanced Research Centre for Powder Metallurgy and New Materials (ARCI), Hyderabad, India
}

Correspondence should be addressed to Koona Ramji; ramji.dmeau@gmail.com

Received 21 July 2018; Accepted 16 May 2019; Published 10 June 2019

Academic Editor: Avraam I. Isayev

Copyright (C) 2019 Roopa Hegde et al. This is an open access article distributed under the Creative Commons Attribution License, which permits unrestricted use, distribution, and reproduction in any medium, provided the original work is properly cited.

\begin{abstract}
Multiwalled carbon nanotubes (MWCNTs) were synthesized by the reduction of ethyl alcohol with sodium borohydride $\left(\mathrm{NaBH}_{4}\right)$ under a strong basic solvent with the high concentration of sodium hydroxide $(\mathrm{NaOH})$. Nanocomposites of different concentration of MWCNT dispersed in poly(3,4-ethylene dioxythiophene) polymerized with poly(4-styrene sulfonate) (PEDOT:PSS) were prepared and deposited on a flexible polyethylene terephthalate (PET) polymer substrates by the spin coating method. The thin films were characterized for their nanostructure and subsequently evaluated for their piezoresistive response. The films were subjected to an incremental strain from 0 to $6 \%$ at speed of $0.2 \mathrm{~mm} / \mathrm{min}$. The nanocomposite thin film with $0.1 \mathrm{wt} \%$ of MWCNT exhibits the highest gauge factor of 22.8 at $6 \%$ strain as well as the highest conductivity of $13.5 \mathrm{~S} / \mathrm{m}$. Hence, the fabricated thin film was found to be suitable for piezoresistive flexible strain sensing applications.
\end{abstract}

\section{Introduction}

Multiwalled carbon nanotubes (MWCNTs) have unique electrical [1] and mechanical properties [2]. The piezoresistive properties of arbitrarily dispersed MWCNT networks in polymer matrix were studied [3].

Carbon nanotubes(CNTs) are effective because of their high aspect ratios that form conductive paths at a very low concentration of CNTs [4]. CNT networks can be visualized as a box of the three-dimensional statistical resistors network model with a tunneling effect between adjacent nanotubes. A percolation behavior between CNT and polymer forms conductive paths because of interconnecting CNTs within the network [5]. The piezoresistivity of the CNT network is a function of the conductive paths formed by CNTs, tunneling between neighboring CNTs and CNT piezoresistivity.

Currently, there are many techniques to produce highquality MWCNT, namely, electric arc discharge [6], chemical vapour deposition (CVD) [7], and laser vaporization [8]. Production of MWCNT by laser ablation and arc discharge methods cannot be scaled up to industrial capacities. However, the CVD method is useful for the large-scale production of MWCNT. In this paper, the synthesis of MWCNT was performed using modified Wolff-Kishner reduction process.

Various investigations were carried out on CNT films $[9,10]$ and CNT/polymer composites [11, 12] for application as strain sensors. CNT film shows weak stress transfer due to bonding by weak van der Waals forces [10]. To overcome 
this drawback, CNTs are integrated into a polymer matrix to decrease the slippage between the adjoining CNTs and improve the stress transfer properties. Hence, CNT/polymerbased nanocomposites are one of the best suitable materials for strain sensing application [13].

Nanocomposite material has at least one of the dimensions of one of its constituents in nanometer scale [14]. Silicon or metals such as $\mathrm{NiCr}$ or $\mathrm{Cu}-\mathrm{Ni}$ on flexible substrates suffer from the ease of fracture under a large applied load [15] and hence polymer-based composites filled with nanoparticles are preferable for their similar application. The conductive polymers with MWCNT as filler combine the electrical, electronic properties of a metal and mechanical properties of a conventional polymer and hence can be used in flexible electronics and strain sensors $[16,17]$.

The polymer, PEDOT (polythiophene derivative, poly(3,4-ethylene dioxythiophene)), shows high conductivity in comparison with other polymers [18]. However, PEDOT has poor solubility in water and organic solvents. The solubility can be improved by using water-soluble polyelectrolyte, such as PSS (poly-(styrene sulfonic acid)) which is dissolved into PEDOT to form a PEDOT: PSS aqueous composite [19].

The piezoresistive study was conducted on pure MWCNT films as well as MWCNT dispersed in various polymer matrixes resulting in MWCNT-polymer nanocomposite films. Fabrication of pure MWCNT films was undertaken by solution/filtration method and the changes in resistance of pure MWCNT were proportional to the applied strain and the temperature effect on the resistance of the film was observed [9]. Polyimide (PI)-MWCNT composites were prepared by in situ polymerization and the nanocomposites showed increasing variation in electrical resistivity with the increasing applied pressure which makes them ideal for fabrication of a polymer pressure sensor [20]. Another piezoresistive response study of MWCNT-PI nanocomposite was demonstrated with different MWCNT concentrations. Here, the surface conductivity of the nanocomposite was determined by atomic force microscopy in current mode. This nanocomposite was proved to be useful for strain sensing element in a microelectromechanical system (MEMS)/nanoelectromechanical system (NEMS) based piezoresistive pressure sensor applications [21]. The typical percolation phenomenon was observed in a nanocomposite with MWCNT as conductive filler and Styrene-ButadieneStyrene (SBS) as a polymer matrix while testing for electrical and mechanical properties. Unlike in the above discussed studies, the resistance of the MWCNT-SBS nanocomposite film decreased rapidly with increasing stress for a low range of stress [22]. The piezoresistive properties of MWCNTpolypropylene nanocomposites for different MWCNT concentrations were characterized above electrical percolation under quasistatic tension. It was observed that, with the increase in MWCNT concentration, the electrical conductivity of the nanocomposites increased monotonically. The sensitivity of nanocomposites was found to be higher for composites with lower MWCNT concentration [23]. The piezoresistive sensors array was developed by screen printing of MWCNT in poly(dimethylsiloxane) (PDMS) matrix on flexible polyethylene terephthalate (PET) substrate. The increase in resistance was recorded in structures under the influence of increasing compressive forces [24]. MWCNTPDMS piezoresistive nanocomposite was studied for an extremely small range of pressure required for finger sensing. MWCNTs were modified by poly(3-hexylthiophene) (P3HT) [25] to attain a homogeneous dispersion and for lowering the percolation threshold of MWCNT in PDMS. MWCNTepoxy nanocomposite was investigated under uniaxial cyclic tensile and compressive loading in low strain range applications. It was observed that the nanocomposite showed stable response and durable behavior after uniaxial tensile and compressive cycles with increasing change in resistance [26]. Another study on piezoresistive properties of MWCNTepoxy composites was conducted by the electrochemical impedance spectroscopy (EIS) where the bend over the sensor area was tested by digital image correlation (DIC) under quasistatic uniaxial tension. A highly deformable nanocomposite consisting of MWCNT in elastic polyurethane was studied under compression, bending, and extending and also exposed to chemical vapors showing corresponding resistance change [27]. Flexible and deformable sensors were developed with MWCNT-latex thin films by spray-coating and integrating it with fabric. Spatial pressure sensing was achieved and validated using an electrical impedance tomography algorithm. The resistivity distribution of the fabric and its changes on application of pressure at different locations were evaluated by the algorithm [28].

The electrical properties of MWCNT-PEDOT: PSS thin films under temperature and humidity effects were studied and it was concluded that this nanocomposite is insensitive to humidity and hence can be used as strain sensors [29]. As brought out above, the PEDOT: PSS is a good material to be used as the polymer matrix since it shows high conductivity and the MWCNT as nanofiller has shown excellent piezoresistive response when dispersed in the polymer matrix for an applied strain. We have investigated the effects of using different wt $\%$ of synthesized MWCNT in PEDOT: PSS on the conductivity, electrical resistance, and a gauge factor of MWCNT-PEDOT: PSS.

\section{Experimental Details}

There are various methods for the synthesis of MWCNT as arc discharge, laser vaporization, pyrolysis, and CVD. In this paper, synthesis of MWCNT was performed using modified Wolff-Kishner reduction process. This is a base-catalyzed process that produces alkane from the corresponding aldehydes or ketones. Aldehydes or ketones are converted to the corresponding hydrazone and thereafter decomposed in the presence of strong basic conditions to yield the reduced alkyl derivative and nitrogen. MWCNTs were synthesized using modified Wolff-Kishner reduction process where it has advantages over other conventional processes such as it is performed under mild conditions, high purity CNTs are produced because no catalysts are added, and the yield is about $50 \%$ relative which is higher than those obtained with other low-temperature methods. MWCNTs were synthesized by the reduction of ethyl alcohol with sodium borohydride 
$\left(\mathrm{NaBH}_{4}\right)$ under a strong basic solvent with the high concentration of sodium hydroxide ( $\mathrm{NaOH})$. Ethyl alcohol (90\%) of $80 \mathrm{~mL}$ volume, sodium borohydride (99.99\%) of $4.2 \mathrm{~g}$, and $15 \mathrm{~mL}$ of $10 \mathrm{M}$ sodium hydroxide (97\%) solution were added to a $250 \mathrm{~mL}$ flask. The mixtures were stirred with a magnetic stirrer for $30 \mathrm{~min}$ and then transferred to a $125 \mathrm{~mL}$ Parr reactor (model 4750, Parr Company, Moline, IL). The Parr reactor was sealed and then kept at $180^{\circ} \mathrm{C}$ for $20 \mathrm{~h}$ in a furnace and cooled down to room temperature. The end products were washed with alcohol and distilled water several times and then dried in a vacuum oven at $60^{\circ} \mathrm{C}$ for $10 \mathrm{~h}$.

Different MWCNT concentrations $(0.025,0.05,0.075$, and $0.1 \mathrm{wt} \%$ ) were dispersed in $0.2 \mathrm{wt} \%$ sodium dodecyl benzene sulfonate (SDBS) by sonication. The prepared dispersion was mixed with PEDOT: PSS at a volume ratio of 1:1 and was magnetically stirred for $15 \mathrm{~min}$ at $1600 \mathrm{rpm}$. MWCNTPEDOT:PSS $(62 \mu \mathrm{L})$ was deposited on a polymer substrate PET $(0.125 \mathrm{~mm}$ thickness) with predefined shape $(1.5 \mathrm{~cm} \times$ $1 \mathrm{~cm}$ ) by spin coating at a spin speed of $200 \mathrm{rpm}$. The thin films were dried and baked in an oven at $70^{\circ} \mathrm{C}$ for 1 hour. Figure 1(a) shows the schematic of MWCNT-PEDOT: PSS thin film and Figure 1(b) shows the prepared films with the film thickness of $5 \mu \mathrm{m}$ measured by Filmetrics F-20 are used for the current investigations.

\section{Results and Discussion}

3.1. X-Ray Diffraction. Phase analysis was studied by using XRay Diffractometer (XRD) with $\mathrm{Cu}-\mathrm{K} \alpha \mathrm{X}$-radiation of wavelength $1.54056 \AA$ at $45 \mathrm{kV}$ and $40 \mathrm{~mA}$. The diffraction was conducted in the Bragg angles between $10^{\circ}$ and $80^{\circ}$ as shown in Figure 2. The XRD patterns of MWCNT, PEDOT:PSS, and MWCNT-PEDOT:PSS nanocomposite thin film are shown in Figure 2. There are two characteristic peaks at $26.2^{\circ}$ and $43.5^{\circ}$, with an interlayer d-spacing of $3.38818 \AA$ and 2.07503 $\AA$, respectively, corresponding to the MWCNT. The XRD patterns of MWCNT-PEDOT:PSS nanocomposite thin film show peak at $25.9^{\circ}$, which is almost identical to the pristine PEDOT:PSS. It is interesting to see that the diffraction peaks of MWCNT at $43.5^{\circ}$ disappeared after the MWCNTPEDOT:PSS nanocomposite was formed.

3.2. TEM Characterization. The MWCNTs were observed under Transmission Electron Microscopy (TEM) using an accelerating voltage of $15 \mathrm{kV}$. The image in Figure 3 reveals a straight morphology of nanotubes. The nanotubes are visible as a bamboo-like structure with closed ends and have many walls aligned parallel to the tube axis.

3.3. FESEM Characterization. Samples of the nanocomposite thin films were investigated by Field Emission Scanning Electron Microscope (FESEM), which is used to perform qualitative analyses on their surface morphology and microstructure. The FESEM, JEOL/JSM-7100F was equipped with detectors of secondary electrons (SE) and an energy dispersive X-ray spectrometer (EDAX). The FESEM was operated using an accelerating voltage of $15 \mathrm{kV}$ at room temperature. FESEM images of MWCNT-PEDOT: PSS film
TABLE 1: Different elements like carbon, sodium, sulfur, and oxygen present in MWCNT-PEDOT:PSS film.

\begin{tabular}{lcc}
\hline Element & Weight\% & Atomic\% \\
\hline C K & 6.83 & 26.16 \\
$\mathrm{Na} \mathrm{K}$ & 0.9 & 1.8 \\
$\mathrm{~S} \mathrm{~K}$ & 3.22 & 4.62 \\
$\mathrm{O}$ & 23.41 & 67.29 \\
\hline
\end{tabular}

in Figure 4(a) showing MWCNT with different diameters $(22.5 \mathrm{~nm}, 30 \mathrm{~nm}$, and $35.6 \mathrm{~nm})$ are observed. FESEM images in Figures 4(d), 4(e), and 4(f) show MWCNT at different magnifications while the images at Figures 4(b) and 4(c) show MWCNT distribution at low and high MWCNT concentration.

3.4. EDAX Analysis. The elemental composition of the MWCNT-PEDOT: PSS film was confirmed by the Energy Dispersive Spectroscopy (EDAX) at room temperature as shown in Figure 5. The EDAX spectrum indicates the presence of carbon, sodium, sulfur, and oxygen at concentrations specified in Table 1.

3.5. Fourier Transform Infrared Spectrometer Studies. Figure 6 shows FTIR (Fourier Transform Infrared Spectrometer) spectra of MWCNT, PEDOT:PSS and MWCNTPEDOT:PSS, respectively. The absorption bands for MWCNTPEDOT:PSS appeared at 997, 1060, 1192, and $1429 \mathrm{~cm}^{-1}$. The vibrations at 1203,1145 , and $1090 \mathrm{~cm}^{-1}$ for PEDOT:PSS may originate from the stretching of $\mathrm{C}-\mathrm{O}-\mathrm{C}$ bond in the ethylene dioxy group. The addition of MWCNT results in a shift of the absorption peak toward the lower wavenumber (from $1203 \mathrm{~cm}^{-1}$ to $1192 \mathrm{~cm}^{-1}$ ). There is a distinct absorption valley around $1000 \mathrm{~nm}$.

3.6. Electrical Properties of MWCNT-PEDOT:PSS. The conductivity of the MWCNT-PEDOT: PSS films containing $0.025 \mathrm{wt} \%, 0.05 \mathrm{wt} \%, 0.075 \mathrm{wt} \%$, and $0.1 \mathrm{wt} \%$ of MWCNT was measured using a four-point probe resistance measurement technique. The electrical conductivity of the films increases with the increase in the $\mathrm{wt} \%$ of MWCNT in the PEDOT: PSS matrix. The maximum conductivity of the MWCNT-PEDOT: PSS thin film for $0.1 \mathrm{wt} \%$ is $13.5 \mathrm{~S} / \mathrm{m}$ and the minimum conductivity is observed at $0.025 \mathrm{wt} \%$ which is $8.5 \mathrm{~S} / \mathrm{m}$ as shown in Figure 7(a). Accordingly, the resistance of the MWCNT-PEDOT: PSS thin films decreases with increase in MWCNT concentration in the PEDOT: PSS as shown in Figure 7(b). Further, it is observed in Figure 7(a) that there is a notable increase in the conductivity in films with more than $0.075 \mathrm{wt} \%$ of MWCNT. The corresponding critical concentration when there is a sudden increase in conductivity is called the percolation threshold.

Higher conductivity of films with higher MWCNT is due to the phenomena of percolation (conductive paths) created by the MWCNT in the PEDOT:PSS matrix and also due to the strong interfacial connection between the MWCNT and the thiophene rings of PEDOT. This enables electronic density 


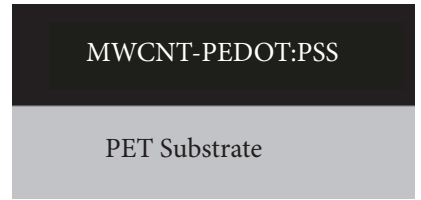

(a)

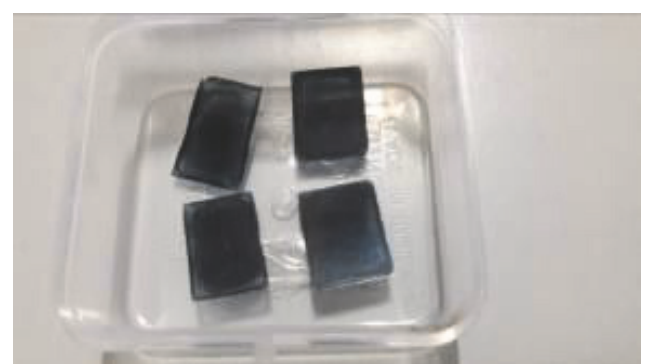

(b)

FIGURE 1: (a) Schematic drawing of the thin film side view. (b) Samples of the prepared MWCNT-PEDOT: PSS thin film.

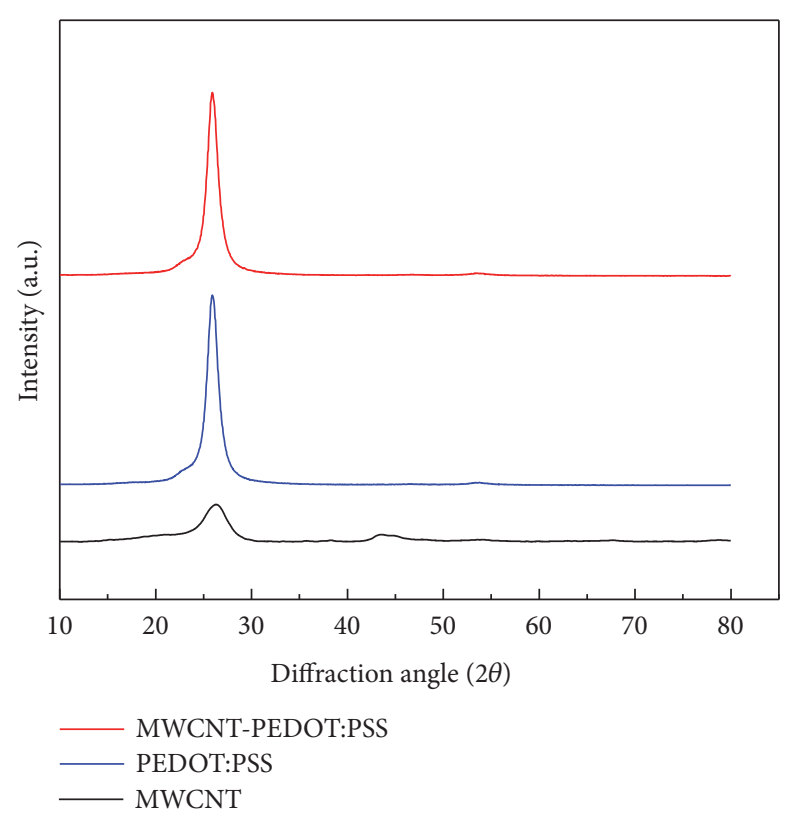

Figure 2: X-ray Diffraction of MWCNT, PEDOT:PSS and MWCNT-PEDOT:PSS nanocomposite thin film.

transfer between them, so the mobile charge carriers are then shifted more in the PEDOT chains.

3.7. Electromechanical Testing. The electromechanical properties of the MWCNT-PEDOT: PSS thin films for different $\mathrm{wt} \%$ of MWCNT were also analyzed using a microtensile test machine as shown in Figure 8 and four-point probe resistance measurement technique. The applied strain was changed from 0 to $6 \%$ at speed of $0.2 \mathrm{~mm} / \mathrm{min}$ using microtensile test machine. The change in the film resistance for corresponding increase in the strain was measured by a four-point probe resistance measurement.

The sheet resistance and relative change in sheet resistance as a function of strain of the MWCNT-PEDOT:PSS thin films for different wt\% of MWCNT were plotted as shown in Figures 9(a) and 9(b). In Figure 9(a), it is observed that the sheet resistance of MWCNT-PEDOT:PSS film increases with the increase in the strain for all wt\% of MWCNT due to the breakdown of existing conductive paths and increase in intertube distances between MWCNT. A high tensile strain on the nanocomposite thin film leads to the tunneling effect between adjacent MWCNT which in turn leads to a sharp increase in the resistance of the nanocomposite. In Figure 9(b), the MWCNT-PEDOT: PSS films show a nonlinear behavior with an exponential increase in relative change in sheet resistance under tension load which is due to the arbitrary distribution of the MWCNT in the film as observed in FESEM images in Figures 4(b) and 4(c).

In order to find how the change in resistance depends upon the material physical quantities, the expression is

$$
R=\frac{\rho l}{A}
$$

where $\mathrm{R}$ is the resistance of a material, $\rho$ is the resistivity of a material, 1 is the length, and $A$ is the area.

$\mathrm{R}$ is differentiated w.r.t. stress $\mathrm{s}$ :

$$
\frac{d R}{d s}=\frac{\rho}{A} \frac{\delta l}{\delta s}+\frac{l}{A} \frac{\delta \rho}{\delta s}-\frac{\rho l}{A^{2}} \frac{\delta A}{\delta s}
$$

Dividing $R=\rho l / A$ on both sides,

$$
\frac{d R}{d s}=\frac{1}{l} \frac{\delta l}{\delta s}+\frac{1}{\rho} \frac{\delta \rho}{\delta s}-\frac{1}{A} \frac{\delta A}{\delta s}
$$

It can be observed that per-unit change in resistance is due to per-unit change in length, per-unit change in area, and perunit change in resistivity.

Gauge factor is defined as the ratio of relative change in resistance with respect to the applied strain. The gauge factor (GF) is given by

$$
G F=\frac{\Delta R / R_{i}}{\varepsilon}=\frac{\left(R_{f}-R_{i}\right) / R_{i}}{\varepsilon}
$$

$R_{f}$ is the final resistance after deformation, $R_{i}$ is the initial resistance without deformation, and $\mathcal{E}$ is the applied strain.

The slope of the graph of relative changes in resistance with the strain from Figure 9(b) is the gauge factor which is defined by (4). As mentioned in Table 2, the highest gauge factor is obtained for $0.1 \mathrm{wt} \%$ of MWCNT in PEDOT: PSS matrix for 6\% strain which is 22.8 evaluated from (4). Highest gauge factor is obtained for $0.1 \mathrm{wt} \%$ of MWCNT in PEDOT: PSS matrix which is the wt $\%$ of MWCNT close to the percolation threshold. The gauge factor in the linear-elastic 


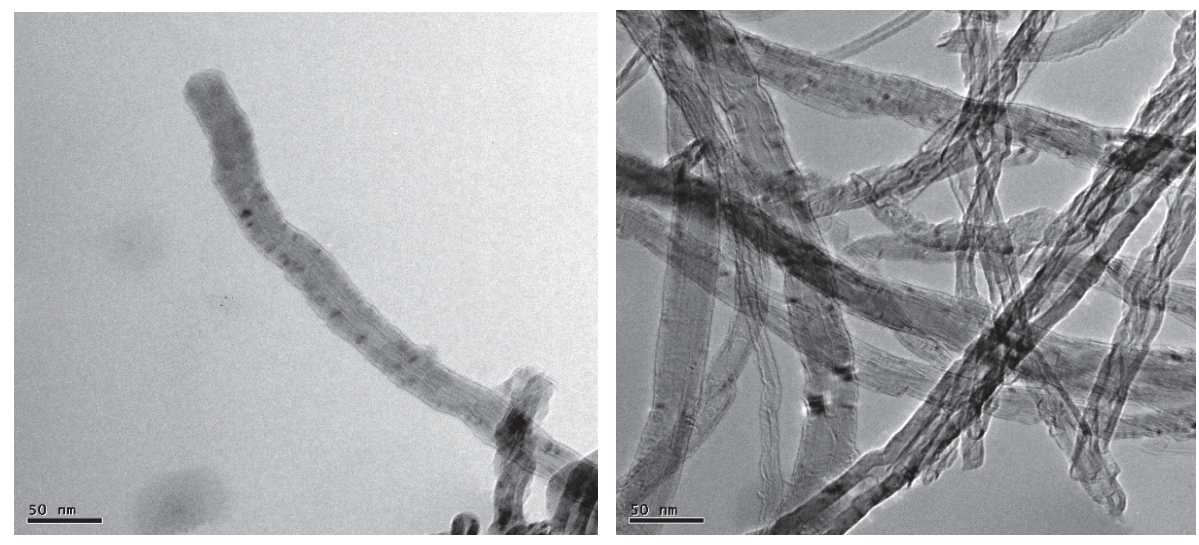

FIGURE 3: TEM images of MWCNT at $50 \mathrm{~nm}$.

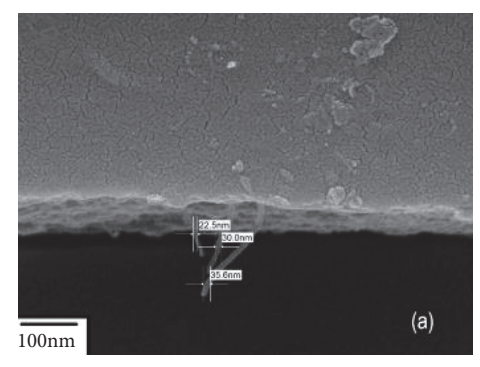

(a)

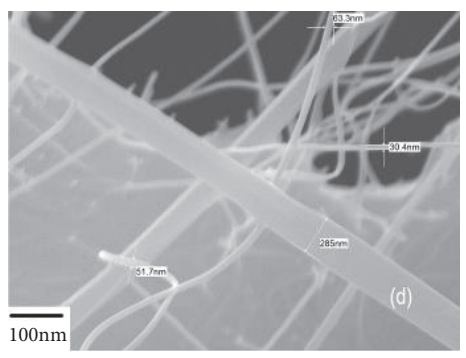

(d)

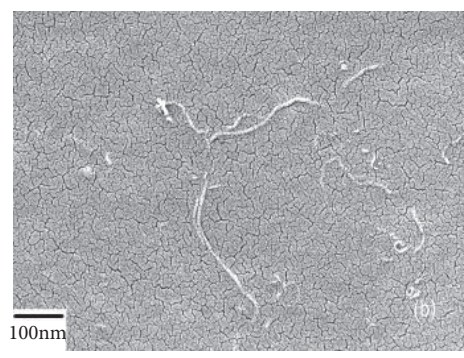

(b)

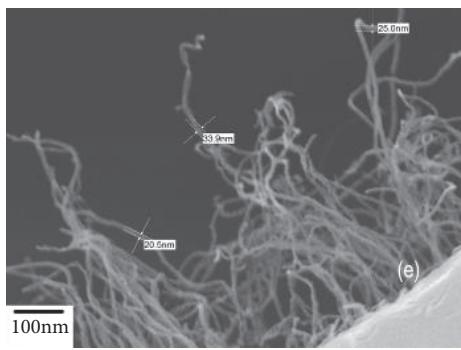

(e)

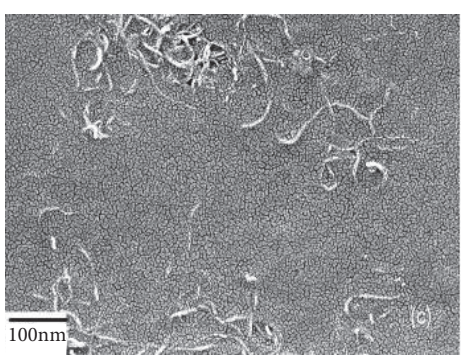

(c)

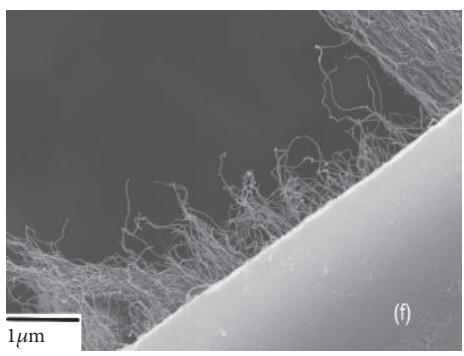

(f)

FIGURE 4: FESEM images of (a) MWCNT-PEDOT:PSS film from the side view showing MWCNT with different diameter, (b) MWCNT at $0.025 \mathrm{wt} \%$, (c) MWCNT at $0.075 \mathrm{wt} \%$, (d) MWCNT at 43,000 magnification, (e) MWCNT at 35,000 magnification, (f) MWCNT at 14,000 magnification.

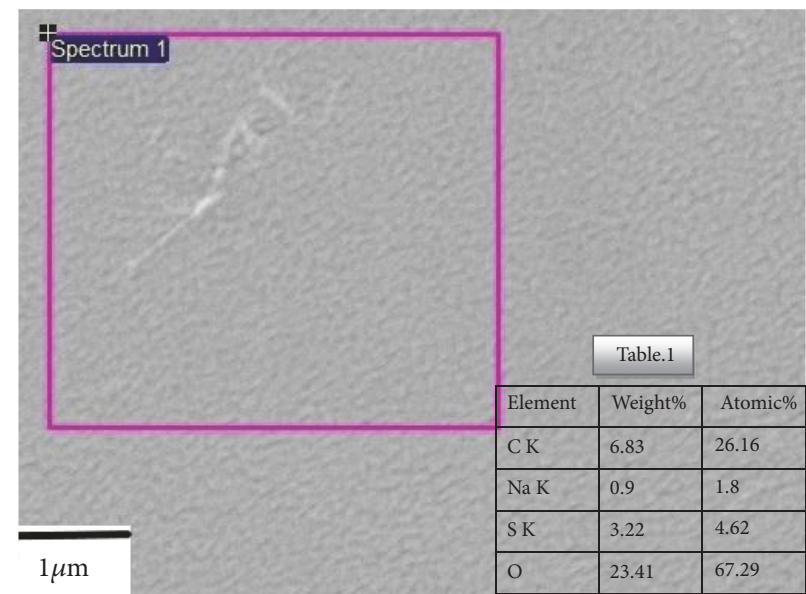

FIGURE 5: EDAX Analysis of MWCNT-PEDOT:PSS film showing different elements mainly carbon, sodium, sulphur, oxygen as shown in Table 1. 


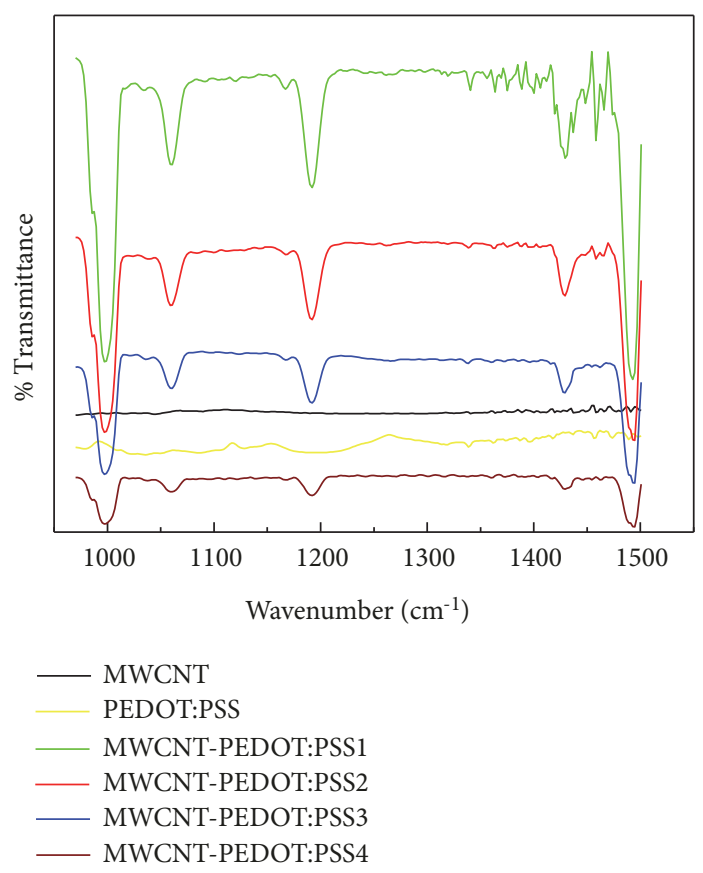

FIGURE 6: FTIR of MWCNT, PEDOT:PSS and MWCNT-PEDOT: PSS films; MWCNT-PEDOT:PSS1-0.025wt\% MWCNT, MWCNTPEDOT:PSS2-0.05wt\% MWCNT, MWCNT-PEDOT:PSS3-0.075wt\% MWCNT, MWCNT-PEDOT:PSS4-0.1wt\% MWCNT.

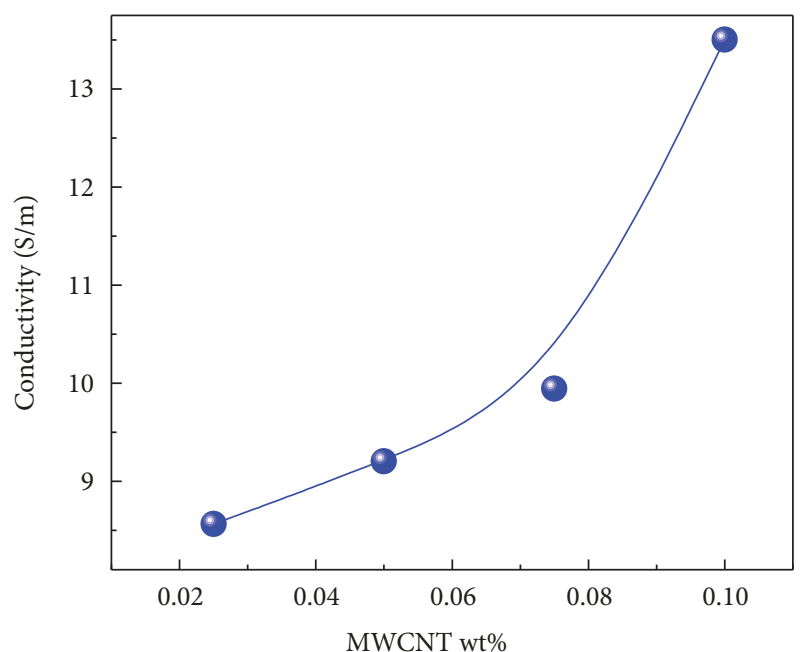

(a)

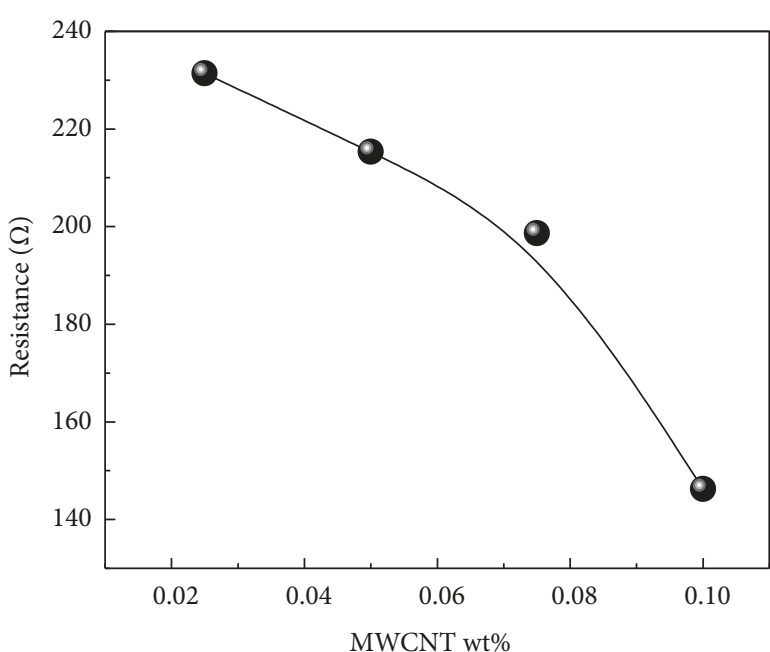

(b)

FIGURE 7: (a) Conductivity of MWCNT-PEDOT: PSS film increases with increasing wt\% of MWCNT. (b) Resistance of MWCNT-PEDOT: PSS film decreases with increasing wt $\%$ of MWCNT.

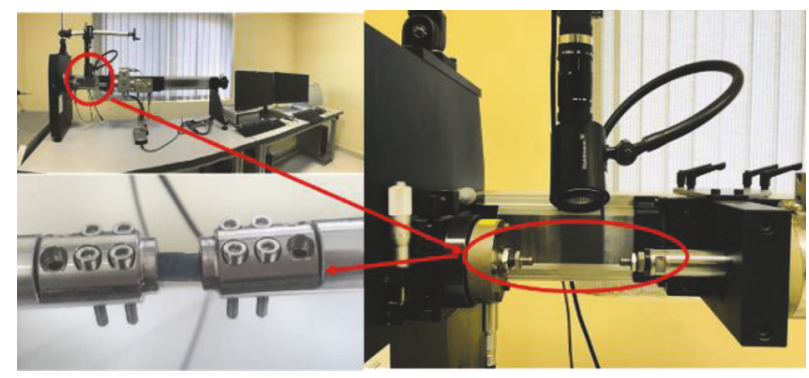

FIGURE 8: Microtensile test machine. 


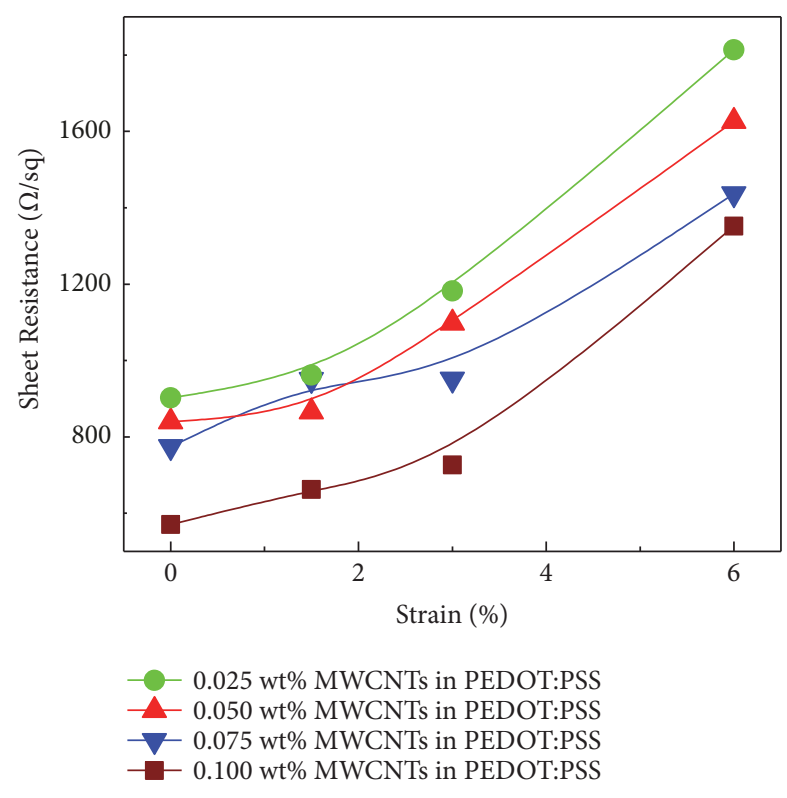

(a)

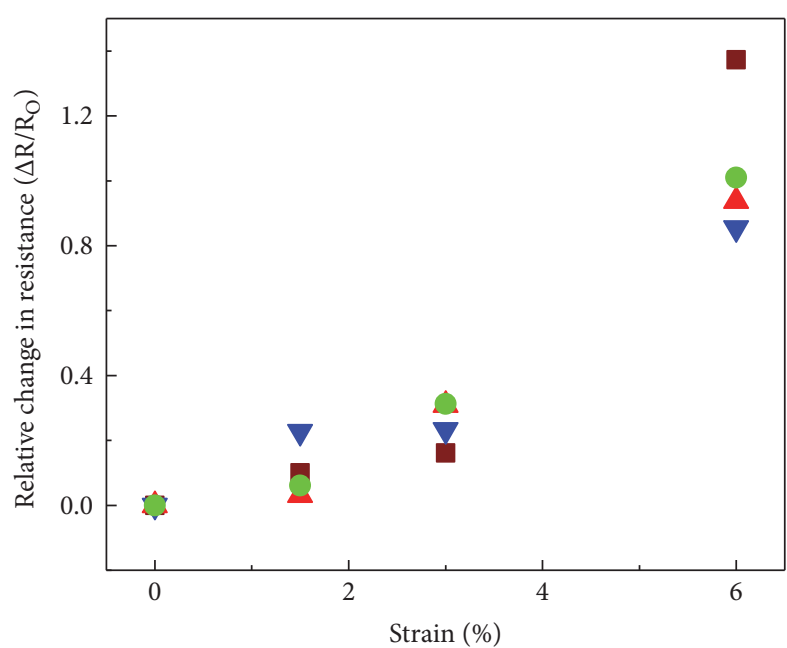

$0.025 \mathrm{wt} \%$ MWCNTs in PEDOT:PSS
$0.050 \mathrm{wt} \%$ MWCNTs in PEDOT:PSS
$0.075 \mathrm{wt} \%$ MWCNTs in PEDOT:PSS
$0.100 \mathrm{wt} \%$ MWCNTs in PEDOT:PSS

(b)

FIgURE 9: (a) Sheet resistance of MWCNT-PEDOT: PSS film increases with increasing Strain \% for different wt\% of MWCNT. (b) Relative change in resistance of MWCNT-PEDOT: PSS film increases with increasing Strain\% for different wt $\%$ of MWCNT.

TABLE 2: Gauge factor of nanocomposite thin film.

Sample Name

$0.025 \mathrm{wt} \%$ MWCNT-PEDOT:PSS

$0.050 \mathrm{wt} \%$ MWCNT-PEDOT:PSS

$0.075 \mathrm{wt} \%$ MWCNT-PEDOT:PSS

$0.100 \mathrm{wt} \%$ MWCNT-PEDOT:PSS
Gauge factor (6\% strain)

16.8347

15.6217

14.2421

22.8782 region of the thin film prepared with $0.3 \mathrm{wt} \%$ MWCNTepoxy by screen printing method was reported as 14.19 [30], which is around 7 times higher than the conventional strain sensors. Hence, the fabricated MWCNT-PEDOT: PSS thin film with $0.075 w t \%$ MWCNT-PEDOT:PSS by spin coating method from our work represents a good gauge factor value of 15.156 in the linear-elastic region observed below $1.5 \%$ strain. From our previous work [31], the highest gauge factor is achieved for $0.05 \mathrm{wt} \%$ of carbon nanospheres (CNS) in PEDOT: PSS matrix for $6 \%$ strain which is 34.57 . Highest gauge factor is obtained for $0.05 \mathrm{wt} \%$ of CNS in PEDOT: PSS matrix which is the wt $\%$ of CNS close to the percolation threshold.

\section{Conclusion}

Synthesis of MWCNT is performed by the reduction of ethyl alcohol with sodium borohydride $\left(\mathrm{NaBH}_{4}\right)$ under a strong basic solvent with the high concentration of sodium hydroxide $(\mathrm{NaOH})$. The MWCNT-PEDOT: PSS nanocomposites for different wt $\%$ of MWCNT have been prepared and this nanocomposite was deposited on the PET thin films by the spin coating technique. Characterization using FESEM revealed the lower concentration of MWCNT for $0.025 \mathrm{wt} \%$ and higher concentration of MWCNT for 0.075 wt\% MWCNT concentration in PEDOT:PSS polymer matrix. Predominantly, MWCNTs with diameters $(22.5 \mathrm{~nm}$, $30 \mathrm{~nm}$, and 35.6nm) are observable in the FESEM images. The maximum conductivity of the MWCNT-PEDOT: PSS thin film for $0.1 \mathrm{wt} \%$ observed was $13.5 \mathrm{~S} / \mathrm{m}$. The piezoresistive behavior of MWCNT-PEDOT: PSS thin films on a flexible substrate was tested on the microtensile tester and fourpoint probe resistance measurement. The conductivity of the thin films decreases as the applied strain increased. The highest gauge factor for $0.1 \mathrm{wt} \%$ of MWCNT in PEDOT: PSS matrix for $6 \%$ strain obtained is 22.8 and it is concluded that the MWCNT-PEDOT: PSS thin film can be used for piezoresistive flexible strain sensing applications.

\section{Data Availability}

The data used to support the findings of this study are available from the corresponding author upon request.

\section{Conflicts of Interest}

The authors declare that they have no conflicts of interest. 


\section{Acknowledgments}

One of the author Gurumurthy Hegde would like to thank DST-Nanomission, Govt of Inida for providing grant with file No SR/NM/NT-1026/2017.

\section{References}

[1] P. R. Bandaru, "Electrical properties and applications of carbon nanotube structures," Journal of Nanoscience and Nanotechnology, vol. 7, no. 4-5, pp. 1239-1267, 2007.

[2] M. M. J. Treacy, T. W. Ebbesen, and J. M. Gibson, "Exceptionally high Young's modulus observed for individual carbon nanotubes," Nature, vol. 381, no. 6584, pp. 678-680, 1996.

[3] B. De Vivo, P. Lamberti, G. Spinelli, and V. Tucci, "Numerical investigation on the influence factors of the electrical properties of carbon nanotubes-filled composites," Journal of Applied Physics, vol. 113, no. 24, p. 244301, 2013.

[4] J. K. W. Sandler, S. Pegel, and M. Cadek, "A comparative study of melt spun polyamide-12 fibres reinforced with carbon nanotubes and nanofibres," Polymer, vol. 45, no. 6, pp. 2001-2015, 2004.

[5] O. Kanoun, C. Müller, A. Benchirouf et al., "Flexible carbon nanotube films for high performance strain sensors," Sensors, vol. 14, no. 6, pp. 10042-10071, 2014.

[6] L. Murr, D. Brown, E. Esquivel, T. Ponda, F. Martinez, and A. Virgen, "Carbon nanotubes and other fullerenes produced from tire powder injected into an electric arc," Materials Characterization, vol. 55, no. 4-5, pp. 371-377, 2005.

[7] A. V. Melechko, V. I. Merkulov, T. E. McKnight et al., "Vertically aligned carbon nanofibers and related structures: controlled synthesis and directed assembly," Journal of Applied Physics, vol. 97, no. 4, Article ID 041301, 2005.

[8] A. Dupuis, "The catalyst in the CCVD of carbon nanotubes-a review," Progress in Materials Science, vol. 50, no. 8, pp. 929-961, 2005.

[9] X. Li, C. Levy, and L. Elaadil, "Multiwalled carbon nanotube film for strain sensing," Nanotechnology, vol. 19, Article ID 045501, 2008.

[10] I. Kang, M. J. Schulz, J. H. Kim, V. Shanov, and D. Shi, "A carbon nanotube strain sensor for structural health monitoring," Smart Materials and Structures, vol. 15, p. 737, 2006.

[11] M. Park, H. Kim, and J. P. Youngblood, "Strain-dependent electrical resistance of multi-walled carbon nanotube/polymer composite films," Nanotechnology, vol. 19, no. 5, Article ID 055705, 2008.

[12] Alamusi, N. Hu, H. Fukunaga, S. Atobe, Y. Liu, and J. Li, "Piezoresistive strain sensors made from carbon nanotubes based polymer nanocomposites," Sensors, vol. 11, no. 11, pp. 10691-10723, 2011.

[13] A. Sanli, C. Müller, O. Kanoun et al., "Piezoresistive characterization of multi-walled carbon nanotube-epoxy based flexible strain sensitive films by impedance spectroscopy," Composites Science and Technology, vol. 122, pp. 18-26, 2016.

[14] P. M. Ajayan, P. Redlich, and M. Ruhle, "Structure of carbon nanotube-based nanocomposites," Journal of Microscopy, vol. 185, p. 275, 1997.
[15] S. Stassi, V. Cauda, G. Canavese, and C. F. Pirri, "Flexible tactile sensing based on piezoresistive composites: a review," Sensors, vol. 14, no. 3, pp. 5296-5332, 2014.

[16] N. Hu, Y. Karube, M. Arai et al., "Investigation on sensitivity of a polymer/carbon nanotube composite strain sensor," Carbon, vol. 48, no. 3, pp. 680-687, 2010.

[17] G. Latessa, F. Brunetti, A. Reale, G. Saggio, and A. Di Carlo, "Piezoresistive behaviour of flexible PEDOT:PSS based sensors," Sensors and Actuators B: Chemical, vol. 139, no. 2, pp. 304309, 2009.

[18] D. J. Lipomi, J. A. Lee, M. Vosgueritchian, B. C.-K. Tee, J. A. Bolander, and Z. Bao, "Electronic properties of transparent conductive films of PEDOT: PSS on stretchable substrates," Chemistry of Materials, vol. 24, no. 2, pp. 373-382, 2012.

[19] C. Yeon, G. Kim, J. W. Lim, and S. J. Yun, "Highly conductive PEDOT:PSS treated by sodium dodecyl sulfate for stretchable fabric heaters," RSC Advances, vol. 7, p. 5888, 2017.

[20] C. Gau, H. S. Ko, and H. T. Chen, "Piezoresistive characteristics of MWNT nanocomposites and fabrication as a polymer pressure sensor," Nanotechnology, vol. 20, no. 18, Article ID 185503, 2009.

[21] K. Singh, J. Akhtar, and S. Varghese, "Multiwalled carbon nanotube-polyimide nanocomposite for MEMS piezoresistive pressure sensor applications," Microsystem Technologies, vol. 20, no. 12, pp. 2255-2259, 2014.

[22] Z. F. Wang, P. Wang, X. Y. Ye, and B. Jiang, "Processing and Modeling of Multi-Walled Carbon Nanotube/StyreneButadiene-Styrene (SBS)Composites for Force Sensing," 2009, 9th IEEE Conference on Nanotechnology (IEEE-NANO).

[23] O. Zetina-Hernández, S. Duarte-Aranda, A. May-Pat et al., "Coupled electro-mechanical properties of multiwall carbon nanotube/polypropylene composites for strain sensing applications," Journal of Materials Science, vol. 48, no. 21, pp. 7587-7593, 2013.

[24] S. Khan, L. Lorenzelli, and R. S. Dahiya, "Bendable piezoresistive sensors by screen printing MWCNT/PDMS composites on flexible substrates," 2014, 10th Conference on Ph.D. Research in Microelectronics and Electronics (PRIME).

[25] J. Hwang, J. Jang, K. Hong et al., "Poly(3-hexylthiophene) wrapped carbon nanotube/poly(dimethylsiloxane) composites for use in finger-sensing piezoresistive pressure sensors," Carbon, vol. 49, no. 1, pp. 106-110, 2011.

[26] A. Sanli, A. Benchirouf, C. Müller, and O. Kanoun, "Piezoresistive performance characterization of strain sensitive multiwalled carbon nanotube-epoxy nanocomposites," Sensors and Actuators A Physical, vol. 254, pp. 61-68, 2017.

[27] P. Slobodian, P. Riha, R. Benlikaya, P. Svoboda, and D. Petras, "A flexible multifunctional sensor based on carbon nanotube/polyurethane composite," IEEE Sensors Journal, vol. 13, no. 10, pp. 4045-4048, 2013.

[28] L. Wang, S. Gupta, K. J. Loh, and H. S. Koo, "Distributed pressure sensing using carbon nanotube fabrics," IEEE Sensors Journal, vol. 16, pp. 4663-4664, 2016.

[29] A. Benchirouf, S. Palaniyappan, R. Ramalingame, P. Raghunandan, T. Jagemann, C. Müller et al., "Electrical properties of multi-walled carbon nanotubes/PEDOT:PSS nanocomposites thin films under temperature and humidity effects," Sensors and Actuators, B: Chemical, vol. 224, pp. 344-350, 2016. 
[30] A. Bouhamed, A. Al-Hamry, C. Müller, S. Choura, and O. Kanoun, "Assessing the electrical behaviour of MWCNTs/epoxy nanocomposite for strain sensing," Composites Part B: Engineering, vol. 128, pp. 91-99, 2017.

[31] R. Hegde, K. Ramji, S. Peravali, and G. Hegde, "Synthesis of carbon nanospheres and piezoresistive study of carbon nanospheres-PEDOT:PSS nanocomposite flexible thin film for strain sensing applications," Materials Research Express, vol. 6, no. 7, p. 076408, 2019. 


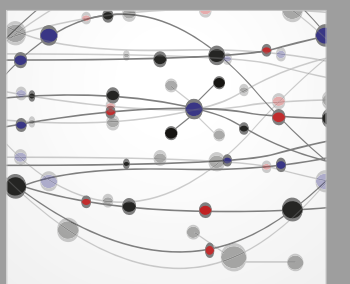

The Scientific World Journal
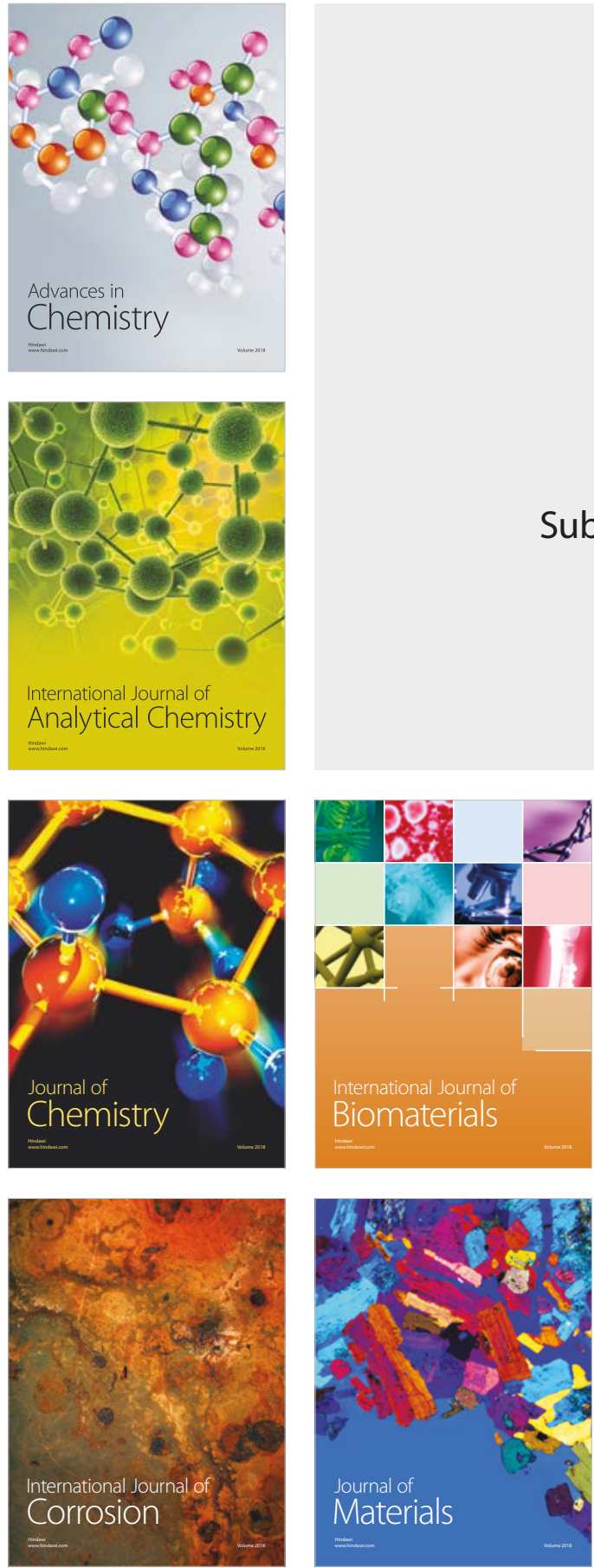

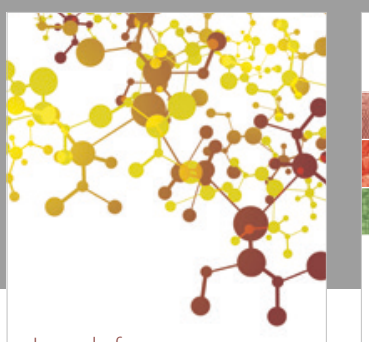

Journal of

Applied Chemistry
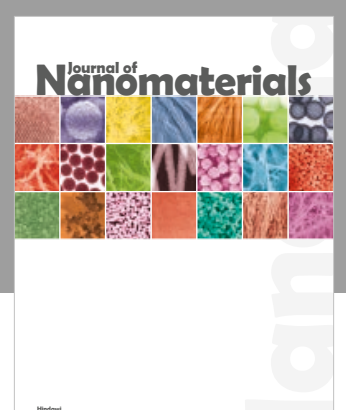

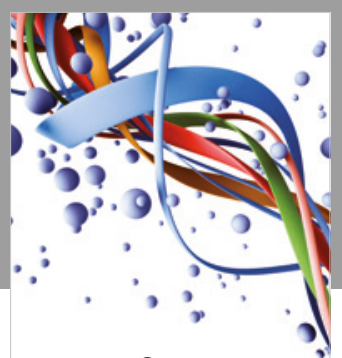

Scientifica

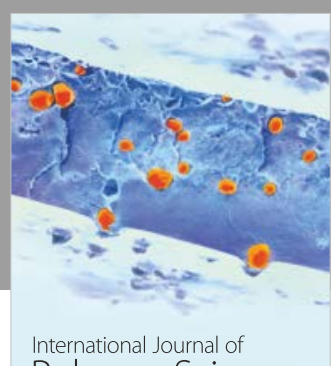

Polymer Science

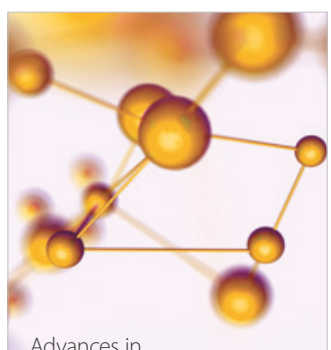

Physical Chemistry
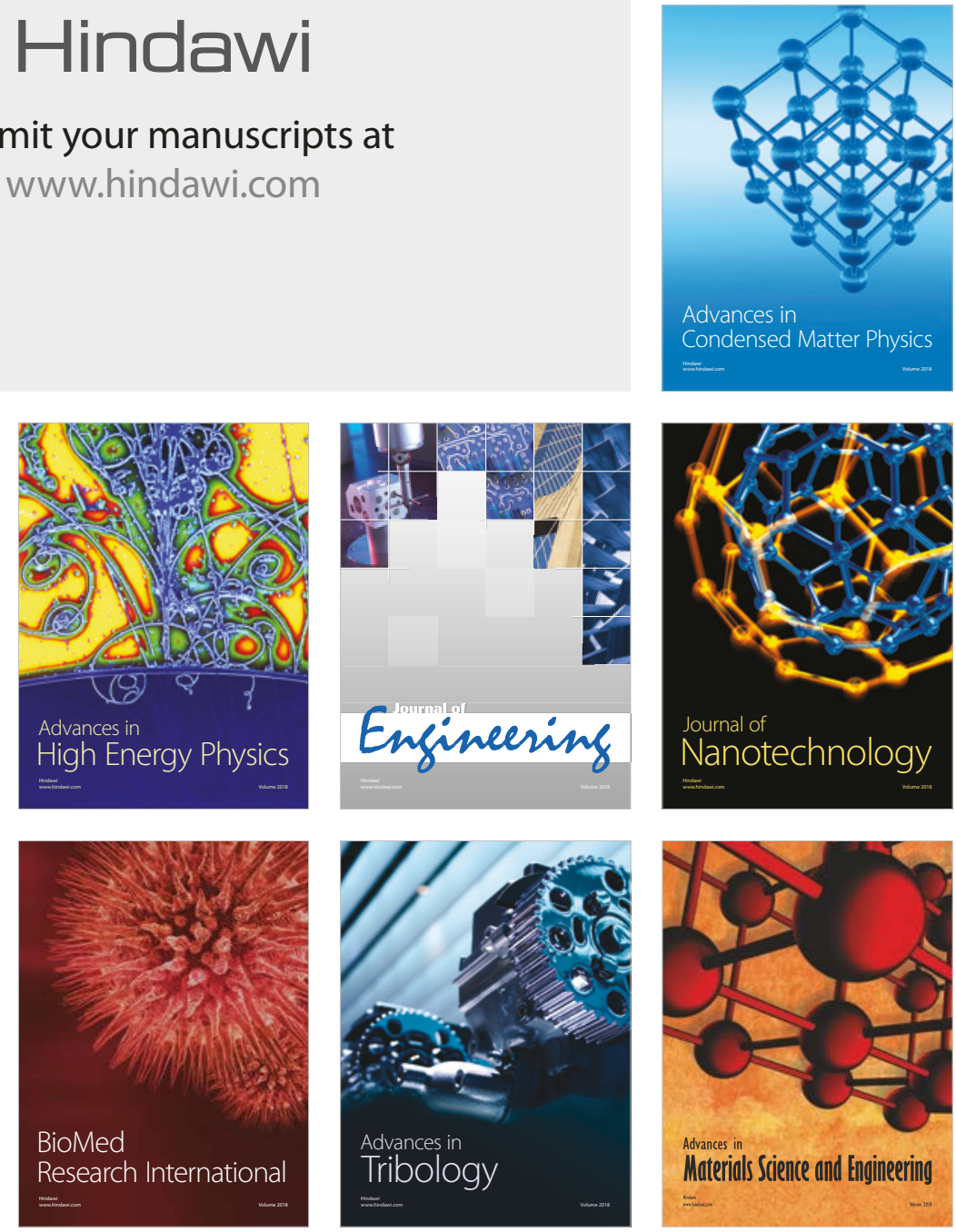